\title{
Costs Optimization for Unit Commitment and Economic Load Dispatch in Large Scale Power Systems
}

\author{
Norhamimi, Student Member, IEEE, Musse Mohamed Ahmed, Member, IEEE, and Ismail Hassan,
} Member, IEEE

\begin{abstract}
Power generation business profit depends on the Power Systems operational costs. Finding an optimal solution to the Unit Commitment (UC) and Economic Load Dispatch (ELD) is one of the smart strategies that being practiced by most of power producers. UC and ELD main problems are to find the minimum total fuel cost and fast computation simulation time scheduling of UC and ELD. Obtaining the best solution to these two problems lead to remarkable saving in the Power system operational cóst. Lagrangian Relaxation (LR) is one of the best solution methods to UC and ELD problems. The approach is more efficient and easier than other methods in solving largescale problems. Lately, the emerging of Bundling Methods (BM) improves the weakness of LR. Through BM, the LR dual functions are updated at the higher fevel. With the use of interior point method as an initialization method this paper presents $L R$ and BM based solution technique to UC and ELD problems. It is based on application of the said techniques to thermal units consisting of 45 generators. A comparison has been made with a data taken from Tenaga Nasional Berhad (TNB) and the results found from this system has been compared to that of TNB results.
\end{abstract}

Index Terms-Bundling Method, Cutting Planes Method, Economic Load Dispatch, Interior Point Method, Lagrangian Relaxation, Lagrangian Multipliers, Lagrangian Dual Problem, Power System Operations, Thermal generation system, Unit Commitment.

\section{NOMENCLATURE}

$N \quad$ number of units

$T \quad$ number of time periods

$U_{i}^{j} \quad$ status of unit i of period j(commit or decommit)

$F_{S C_{i}}$ startup cost of unit i

$P_{D}^{j} \quad$ power demand of period $\mathrm{j}$

$P_{i}^{j} \quad$ output power level of unit $\mathrm{i}$ of period $\mathrm{j}$

$\propto_{i}^{j} \quad$ startup and shutdown indicator of unit $i$ in period $j$

$P_{i}^{\max }$ maximum capacity constraint of unit $i$

$F_{1}\left(P_{i}\right)$ the generation cost as a function of output power level of unit $i$

$S_{R}^{j} \quad$ the forecasted system spinning reserve requirement of period j

$\delta P_{i}^{+} \quad$ maximum loading rate for unit $\mathrm{i}$

$\delta P_{i}^{-} \quad$ maximum deloading rate for unit $\mathrm{i}$

$T s d_{i}^{\text {min }}$ the minimum shut down time of unit i

Tup $p_{i}$ nunning time of unit $\mathbf{i}$

$T u p_{i}^{\text {min }}$ the minimum up time of unit $i$

$P_{\text {Lass }}$ network power losses

$k_{i} \quad$ the reserve value constant of unit $\mathrm{i}$

$T r u_{i}$ ramp up rate limit of unit $i$

$T r d$, ramp down rate limit of unit $i$

$C c_{i}$ cooling part of the startup cost of unit $i$.

$\tau \quad$ cooling time constant of thermal unit $i$.

$C f_{i}$ fixed cost (startup maintenance cost).

$\mathrm{Fl}_{i} \quad$ fuel cost of unit $\mathrm{i}$.

$C h$, the hot startup cost of thermal unit i.

\section{INTRODUCTION}

Qptimization problems in the power generation industry have attracted researchers, power producers and power experts for many years. The complex nature of generation of electricity implies ample opportunity of improvement towards the optimal power generation solution. The demand of power systems varies throughout the day and reaches a different peak values from one day to another. To satisfy this demand, to start-up and shutdown a number of generating units at various power stations each day is needed. Due to this, Unit Commitment (UC) and Economic Load Dispatch (ELD) problems play major role on finding an optimal power scheduling in electrical power system. The major problems are to decide when and which generating units to turn on and turn off and at the same time minimize the total fuel cost over specified period subject to a large number of difficult constraints. The most important constraint is that the total 